\title{
General practitioners in German metropolitan areas - distribution patterns and their relationship with area level measures of the socioeconomic status
}

\author{
Jan Bauer ${ }^{*}$ D, Doerthe Brueggmann, Daniela Ohlendorf and David A. Groneberg
}

\begin{abstract}
Background: Geographical variation of the general practitioner (GP) workforce is known between rural and urban areas. However, data about the variation between and within urban areas are lacking.

Method: We analyzed distribution patterns of GP full time equivalents (FTE) in German cities with a population size of more than 500,000. We correlated their distribution with area measures of social deprivation in order to analyze preferences within neighborhood characteristics. For this purpose, we developed two area measures of deprivation: Geodemographic Index (GDI) and Cultureeconomic Index (CEI).

Results: In total $n=9034.75$ FTE were included in $n=14$ cities with $n=171$ districts. FTE were distributed equally on inter-city level (mean: 6.49; range: 5.12-7.20; SD: 0.51). However, on intra-city level, GP distribution was skewed (mean: 6.54; range: 1.80-43.98; SD: 3.62). Distribution patterns of FTE per 10^4 residents were significantly correlated with GDI $(r=-0.49 ; p<0.001)$ and CEI $(r=-0.22 ; p=0.005)$. Therefore, location choices of GPs were mainly positively correlated with 1) central location $(r=-0.50 ; p<0.001)$, 2) small household size of population $(r=-0.50 ; p<0.001)$ and 3) population density $(r=0.35 ; p<0.001)$.

Conclusion: Intra-city distribution of GPs was skewed, which could affect the equality of access for the urban population. Furthermore, health services planners should be aware of GP location preferences. This could be helpful to better understand and plan delivery of health services. Within this process the presented Geodemographic Index (GDI) could be of use.
\end{abstract}

Keywords: Primary care, Access, Distribution, Urban, Socioeconomic status

\section{Background}

Discrepancies in access, supply and demand of primary care constitute an intensified focus of health care legislation worldwide. Many European countries face a shortage of general practitioners (GPs), e.g. for the UK, an additional need of approximately 8000 full-time GPs is projected by 2020 [1]. Furthermore, the occupational profile of GPs is perceived as unattractive based on suboptimal salaries, administrative burdens and an increasing complexity of care [2]. Thus, many junior physicians pursue training in other specialties [2]. However, several solutions

\footnotetext{
* Correspondence: j.bauer@med.uni-frankfurt.de Institute of Occupational, Social and Environmental Medicine, Goethe University, Theodor-Stern-Kai 7, 60329 Frankfurt/Main, Germany
}

have been proposed to this shortage without the need for more trained GPs. These solutions mainly focused on the empowerment of non-physician workforce [3, 4].

In addition to decreasing absolute provider numbers, relative numbers in terms of the spatial distribution of the GP workforce vary geographically. This spatial distribution has been shown to depend on numerous socioeconomic and demographical factors: Large demographic studies identified a shortage of providers located in the countryside and a relative oversupply in metropolitan areas leading to a mismatch of demand and supply $[5,6]$. Similar to the GP distribution (supply), population sizes (demand) vary geographically: people are migrating towards large urban centers to pursue job opportunities 
or further education [7]. In addition, the populations' socioeconomic status (SES) as a major determinant of health inequity has also been shown to vary geographically [7]. Furthermore a low SES has been linked to a poor health status with a higher rate of overall mortality [7-10]. In particular, morbidities such as cardiovascular events, stroke or diabetes are more common among the socially deprived population [11-13].

In order to manage local provider shortages in European countries, spatial distribution of GPs has been regulated [6]. In Germany, administrative areas (planning areas) have been installed for which the number of GPs is restricted. This restriction takes effect if a populationto-GP ratio of 1:1671 is exceeded by $10 \%$ [14]. However, within these restricted administrative areas, a GP can choose his or her preferred practice location. Since measurements based on population-to-provider ratios (PPR) have limitations, the current capacity plan has become subject of recent discussions [15]. In this context, little is known about the factors associated with settlement decisions of GPs in metropolises. So far, numerous studies have focused on urban vs. rural comparisons of GP distribution and their impact on health inequity [16-22]. Only few studies have investigated metropolitan areas in Germany [23, 24]. Therefore, the objectives of this study were (1) to compare spatial distribution of GPs on intraand inter-city level, (2) to relate the distribution pattern to the geo-social environment defined by the populations' SES and (3) to extract urban location choice preferences of GPs.

\section{Methods}

In this study, we investigated 14 German metropolises with a population size of more than 500,000 according to Census data from 2013. Thus, the following cities were included (in declining population size order): Berlin, Hamburg, Munich, Cologne, Frankfurt, Düsseldorf, Stuttgart, Dortmund, Essen, Leipzig, Bremen, Dresden, Hanover and Nuremberg. All cities are shown in Fig. 1.

The analysis was performed on the largest-scale city division, for which statistical data were available. These were defined as city districts (total of $n=171$ districts in $n=14$ cities). The total population size for all districts was $n=13,638,160$.

\section{Data sources and measures of outcome variables}

GP Data: Data were obtained from the National Association of Statutory Health Insurance Physicians in Germany (KBV). GPs were defined as physicians actively participating in primary care. According to $\mathbb{} 11$ (2) of the 'directive of capacity planning' by the Federal Joint Committee, physicians of the following medical specialties can account as GPs: 1) family medicine, 2) internal medicine and 3) physicians without specialization.
The number of GPs was measured by their full time equivalent (FTE) in regard to their contracted participation in the delivery of primary care $(\mathbb{S} 21$ and $\mathbb{\$} 22$ 'directive of capacity planning'). Therefore, the range of FTE of a single GP can range between 0 (no participation) and 1 (full participation) with steps of 0.25. The number of FTE per district was obtained from the KBV.

Geographic data: City district boundaries were retrieved from communal administrative bureaus. Additionally, the internet-based tracking software GPSies [25] in combination with official district maps has been used for headsup digitizing. City district boundaries are created and regularly revised by local authorities due to political and/or geographical changes. We applied city district boundaries as of 2013. Furthermore, coordinates of each city center $(n=14)$ were retrieved via Google Maps (Google Inc., Mountain View, USA). The city center was defined as the respective city hall.

Socioeconomic status (SES): Indicator data of SES were retrieved from official city statistics. We obtained the latest data available as of 2015 (oldest data as of 2010; mostly 2014). In total, $n=10$ indicator variables were used (see Table 1). These variables were chosen based on their theoretical influence on the SES and their availability on city district level.

\section{Calculations and statistical analysis}

Data of GPs and population sizes on district level were used to build population-to-provider ratios (PPR) as measures of spatial distribution $\left(\mathrm{PPR}=\mathrm{FTE}\right.$ per $10^{\wedge} 4$ residents $)$ [16]. In addition, linear airline district-city-center distances were calculated (from mean district coordinates to city hall coordinates) with the software QGIS (QGIS Development Team, General Public License). We standardized all measures by computing z-scores individually for each city. Hereby, inter-city district data were comparable.

\section{Development of SES composite indices}

A principal component analysis (PCA) was performed with all $n=10$ SES indicators to create composite indices. Eligible indicators were tested by using the measure of sample adequacy (Kaiser-Meyer-Olkin) and the Bartlett's test of sphericity. The composite indices represented area measures of SES. According to PCA results, index scores were calculated with a regression method (scores have a mean of 0 ; variance is equal to the squared multiple correlation between estimated score and true value). Again, $\mathrm{z}$-scores were computed to standardize inter-city comparison. Furthermore, a correlation analyses (Spearman's Rho) was performed using SPSS 23 (IBM, Armonk, USA). For the correlation, we applied the following definitions:

- $r<|0.2|$ : no relevant correlation.

- $|0.2| \leq r<|0.3|$ : weak correlation. 

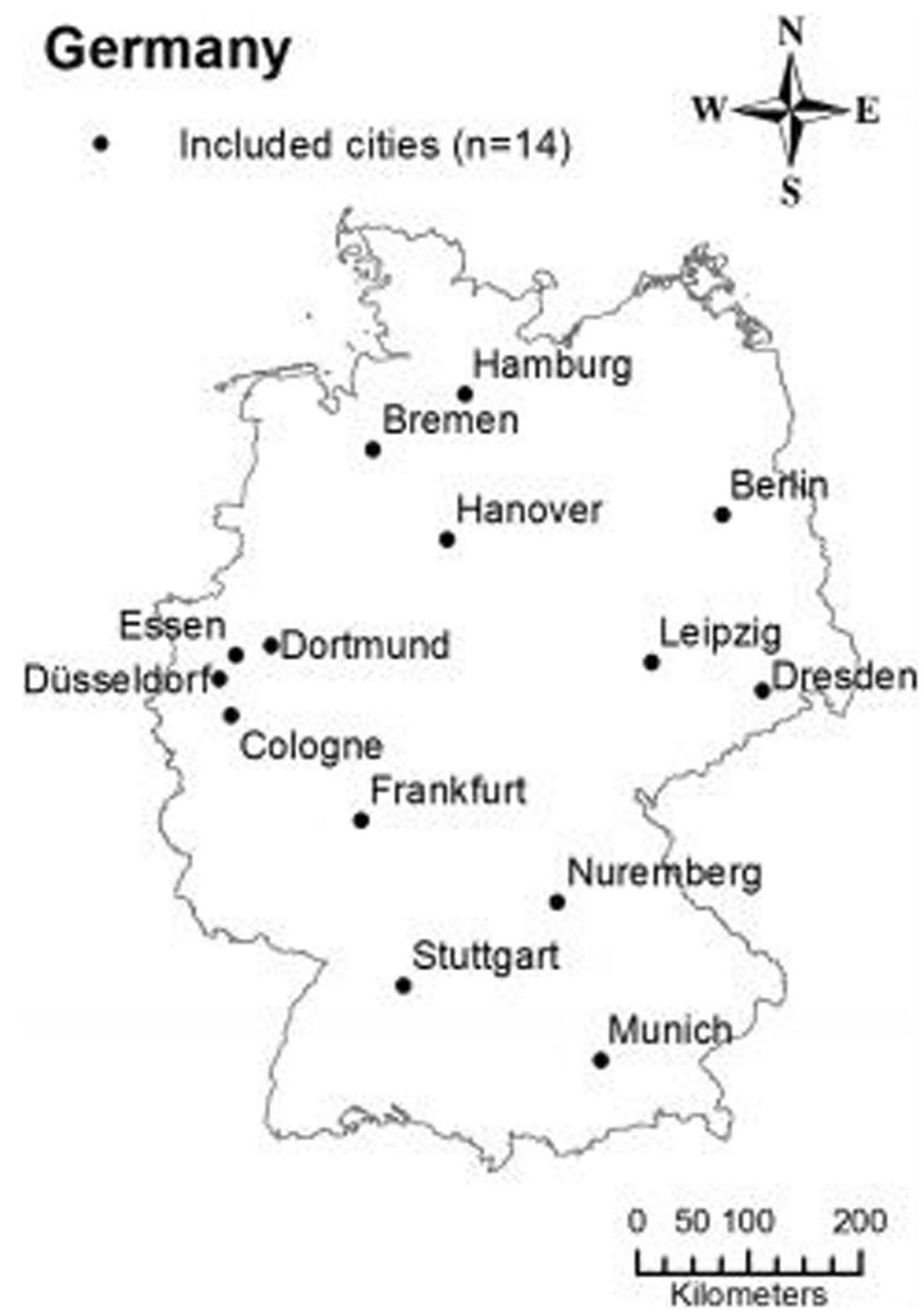

Fig. 1 Included cities $(n=14)$ in Germany. This figure is a derivative of geographic data provided by the "Federal Agency for Cartography and Geodesy" ๑ GeoBasis-DE/BKG 2013. The permission to use and adapt this figure is stated in the "GeoNutzV (\$2)" [45]

Table 1 Demographic data and SES indicators

\begin{tabular}{lll}
\hline Indicator & Description & Unit \\
\hline $\begin{array}{l}\text { Population density } \\
\text { Distance to city hall }\end{array}$ & Number of residents per $\mathrm{km}^{2}$ & $\mathrm{n} / \mathrm{km}^{2}$ \\
$\begin{array}{l}\text { Old-age dependency ratio } \\
\text { Migrant quota }\end{array}$ & $\begin{array}{l}\text { Number of residents over } 65 \text { years per } 100 \text { residents aged 15-64 years } \\
\text { Quota of residents with migration background to all residents (migration background was defined } \\
\text { as foreign citizenship or dual citizenship or background of parental foreign citizenship) }\end{array}$ \\
Household size & Average number of residents per household \\
Employment quota & Quota of employed residents subject to social insurance contribution to all residents aged 15-64 \\
Unemployment quota & Quota of unemployed residents to all residents aged 15-64 \\
Benefits recipients quota & Quota of unemployed residents aged 15-64 receiving state subsidy to all residents aged 15-64 \\
Motorization rate & Number of privately used automobiles per 1000 residents \\
Mortality & Number of deaths per 1000 residents & $\%$ \\
\hline
\end{tabular}


- $|0.3| \leq r<|0.5|$ : mild correlation.

- $|0.5| \leq r<|0.7|$ : strong correlation.

- $r \geq|0.7|$ : very strong correlation.

We further performed a multiple linear regression analysis. Prior, we also tested for its assumptions: 1) linearity, 2) normality, 3) homoscedasticity, 4) independence of observations, 5) multicollinearity and 6) assumptions according to the Gauss-Markov theorem. Model assumptions were controlled for visually (boxplot and histogram), with the Durbin-Watson test and the variance inflation factor.

\section{Results}

In total $n=9034.75$ FTE were located within boundaries of the 14 metropolitan cities. However, in 10 out of 171 districts the number of FTE was less than five and due to data protection, the exact number could not be obtained. For statistical reasons the number of FTE for these districts was set to $n=2.5$. An overview of the cities and the number of FTE is shown in Table 2.

On city level, spatial distribution of GPs in terms of FTE per $10^{\wedge} 4$ residents (PPR) was homogenous with a mean PPR of 6.49 (range: 5.12-7.20; SD: 0.51). However, on district level inhomogeneous spatial distribution was present with a wider range of PPRs (range: 1.80-43.98) and a greater standard deviation (SD: 3.62). Still, the mean PPR was similar with 6.54. Looking at individual cities, the analysis revealed a differing city district variation: A high variation was present in Munich (SD: 7.78) whereas low variation was present in Hamburg (SD: 0.80).
In Fig. 2, the spatial distribution of GPs on district level is shown for Berlin and Frankfurt. In conclusion, unlike inter-city distribution, the intra-city distribution was inhomogeneous.

\section{Results of PCA}

In total, $n=10$ SES indicators were tested eligible for the principal component analysis (PCA). Visualization of scree plot suggested a two-component solution. Two variables with communalities after extraction of $<0.4$ were dismissed: 'Mortality' (communality $\mathrm{x}=0.267$ ) and 'employment quota' (communality $\mathrm{x}=0.128$ ). PCA was repeated with $n=8$ indicators resulting in two composite area measures of SES named (1) Geodemographic Index (GDI) and (2) Cultureeconomic Index (CEI). Results of the PCA are displayed in Table 3.

GDI was mainly loaded with the following indicators: population density, distance to city hall, old-age dependency ratio, household size and motorization rate. CEI was mainly loaded with migrant quota, unemployment quota, and benefits recipients' quota. The total variance explained by both indices was $78.6 \%$. After rotation GDI explained $43.1 \%$ and CEI $35.5 \%$ of total variance.

\section{Correlation of area measures of SES and spatial distribution of FTE}

As seen in Fig. 3, a significant mild negative correlation was present between the spatial distribution of FTE and the Geodemographic Index (GDI) with a negative correlation of $r=-0.49(p<0.001)$. Considering the indicators

Table 2 Overview of cities, population and FTE

\begin{tabular}{|c|c|c|c|c|c|c|}
\hline \multirow{3}{*}{$\begin{array}{l}\text { Metropolitan cities } \\
\text { (number of districts) }\end{array}$} & \multirow{3}{*}{$\begin{array}{l}\text { Population } \\
\text { (n) }\end{array}$} & \multirow{3}{*}{$\begin{array}{l}\text { Population Density } \\
\left(n / \mathrm{km}^{2}\right)\end{array}$} & \multicolumn{4}{|l|}{ FTE } \\
\hline & & & $\varnothing \mathrm{FTE} /$ district & residents/FTE & PPR (SD) & Supply level \\
\hline & & & $(n)$ & $(n)$ & $(n)$ & $(\%)$ \\
\hline Berlin $(n=12)$ & $3,562,166$ & 3995 & 198 & 1496 & $6.68(1.07)$ & 120 \\
\hline Hamburg $(n=7)$ & $1,788,994$ & 2369 & 176 & 1449 & $6.90(0.80)$ & 118 \\
\hline Munich $(n=25)$ & $1,490,678$ & 4797 & 43 & 1388 & $7.20(7.78)$ & 122 \\
\hline Cologne $(n=9)$ & $1,053,528$ & 2602 & 79 & 1486 & $6.73(2.14)$ & 116 \\
\hline Frankfurt $(n=16)$ & 693,342 & 2792 & 28 & 1526 & $6.55(2.37)$ & 119 \\
\hline Düsseldorf $(n=10)$ & 603,210 & 2784 & 40 & 1494 & $6.69(2.10)$ & 115 \\
\hline Stuttgart $(n=23)$ & 592,898 & 2863 & 16 & 1594 & $6.27(3.30)$ & 105 \\
\hline Dortmund $(n=12)$ & 589,283 & 2099 & 25 & 1955 & $5.12(1.41)$ & 111 \\
\hline Essen $(n=9)$ & 576,691 & 2805 & 38 & 1700 & $5.88(1.07)$ & 124 \\
\hline Leipzig ( $n=10)$ & 551,870 & 1854 & 37 & 1512 & $6.61(1.37)$ & 110 \\
\hline Bremen $(n=4)$ & 548,547 & 1726 & 74 & 1488 & $6.72(3.31)$ & 112 \\
\hline Dresden $(n=10)$ & 541,304 & 1649 & 33 & 1619 & $6.18(0.94)$ & 102 \\
\hline Hanover $(n=13)$ & 528,879 & 2591 & 27 & 1524 & $6.56(2.65)$ & 113 \\
\hline Nuremberg $(n=10)$ & 516,770 & 2771 & 35 & 1474 & $6.78(2.38)$ & 117 \\
\hline
\end{tabular}

"Supply levels" describe the official supply of GPs (in \%) for each city as calculated by the KBV [46] as of 2015 (Geographical base of calculating supply levels differed from statistic boundaries used in this study). $\varnothing$ : city average. FTE full time equivalent in regard to their contracted participation in primary care, PPR FTE per $10 \wedge 4$ residents (see Methods section for further details). SD Standard Deviation 


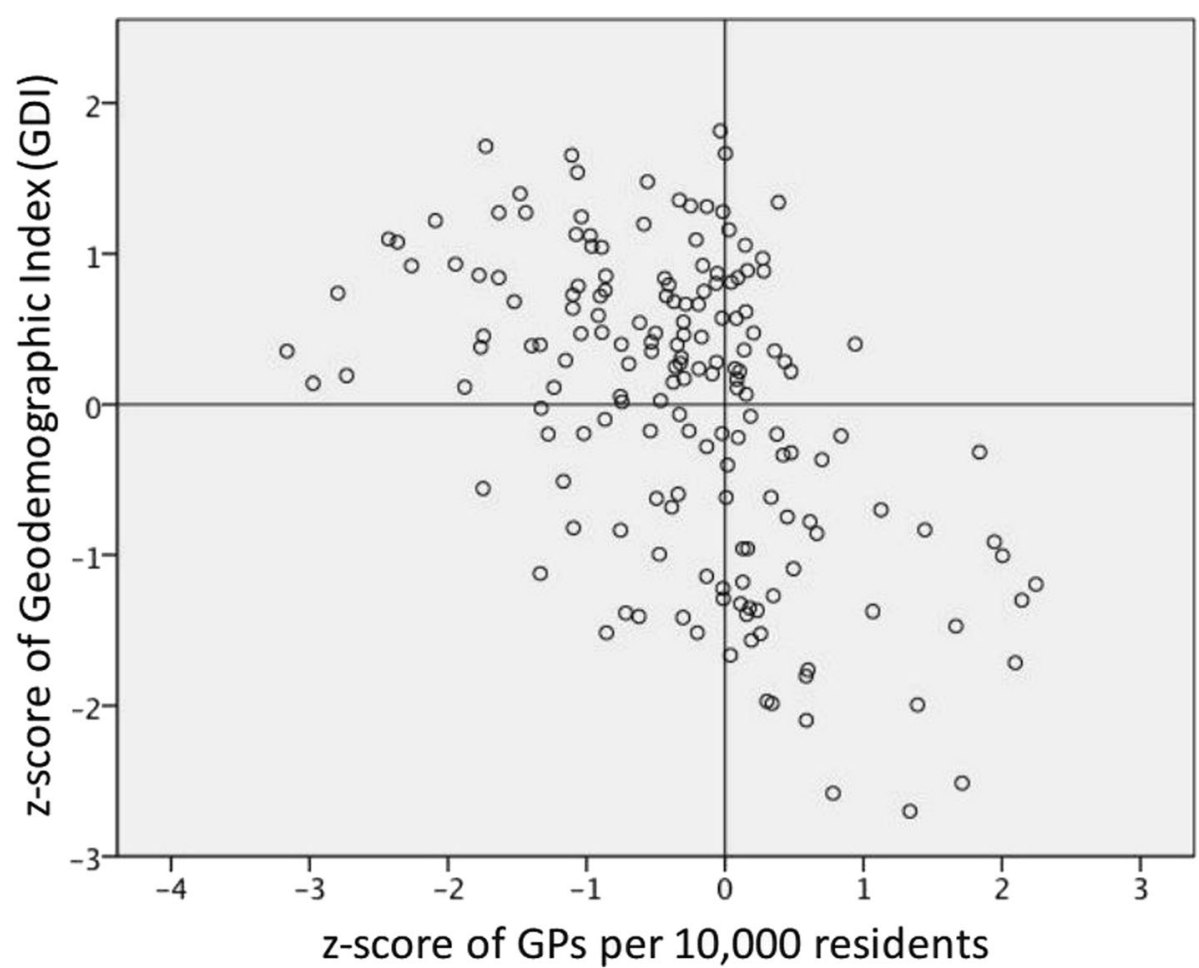

Fig. 2 Residents per full time equivalent (FTE) for districts in Berlin $(n=12)$ and Frankfurt $(n=16)$. This figure is a derivative of "RBS-Blöcke, Dezember 2015" by "Amt für Statistik Berlin-Brandenburg" used under license CC BY 3.0 DE and "Frankfurter Stadtteilgrenzen für GIS-Systeme" by "Bürgeramt, Statistik und Wahlen" used under license dl-de/by-2-0

comprising GDI, we ranked the indicators that were positively correlated with the number of FTE in the respective district in declining order:

1. Central location (indicator: distance to city hall).

2. Small household size (indicator: household size).

3. Crowded district (indicator: population density).

4. Low motorization rate (indicator: motorization rate).

Table 3 Results of PCA

\begin{tabular}{lcccccr}
\hline Indicator & \multicolumn{2}{c}{ Index loading } & & \multicolumn{2}{c}{ Index coefficient } \\
\cline { 2 - 3 } & \multicolumn{1}{c}{ GDI } & CEl & & GDI & \multicolumn{1}{c}{ CEl } \\
\hline Population density & $\mathbf{- 0 . 8 0 9}$ & 0.047 & & -0.242 & -0.040 \\
Distance to city hall & $\mathbf{0 . 9 0 9}$ & -0.044 & & 0.273 & 0.049 \\
Old-age dependency ratio & $\mathbf{0 . 7 4 2}$ & -0.192 & & 0.212 & -0.018 \\
Migrant quota & -0.225 & $\mathbf{0 . 8 6 0}$ & -0.007 & 0.301 \\
Household size & $\mathbf{0 . 8 6 9}$ & 0.121 & & 0.272 & 0.107 \\
Unemployment quota & -0.058 & $\mathbf{0 . 9 6 2}$ & & 0.051 & 0.350 \\
Benefits recipients quota & 0.029 & $\mathbf{0 . 9 7 0}$ & & 0.078 & 0.360 \\
Motorization rate & $\mathbf{0 . 7 8 1}$ & -0.423 & & 0.207 & -0.100 \\
\hline
\end{tabular}

Index loading is based on a rotated component matrix (rotation method: Varimax with Kaiser normalization; bold numbers indicate high loading of indicator in index). Index coefficient was based on the component score coefficient matrix (coefficients by which indicators were multiplied to build GDI and CEI). PCA principal component analysis, GDI geodemographic index CEI cultureeconomic index
5. Young district (indicator: old-age dependency ratio).

In regard to CEI, a significant negative correlation $(r=-0.22 ; p=0.005)$ was found. This result indicated that CEI can explain GP settlement decisions to a lesser extent compared to GDI. Still, focusing on the indicators comprising CEI, we can deduce that a low migrant quota, low unemployment quota, and low benefits recipient quota has potentially positive effects on the number of FTE per district.

These findings were confirmed by a correlation analysis (see Table 4): The indicators "mortality" and "employment quota", which were excluded by the PCA, showed no significant correlation with the spatial distribution of GPs (PPR). Furthermore, a correlation of $r=-0.50(p<0.001)$ for both "distance to city hall" and "household size" with PPR was revealed.

We further performed a multilevel regression analysis allowing for multi-membership (Table 4). We included all indicators that showed a relevant correlation $(r>0.2)$ in the correlation analysis $(n=6)$. The analysis revealed that the regression model was significant (F-test: $p<0.001$ ) and showed no relevant multicollinearity (Durbin-Watson test: 2.247). The corrected coefficient of determination was $\mathrm{R}^{2}=0.332$, which showed that $33 \%$ of the PPR variability has been accounted for. Therefore, the Cohens' effect size 

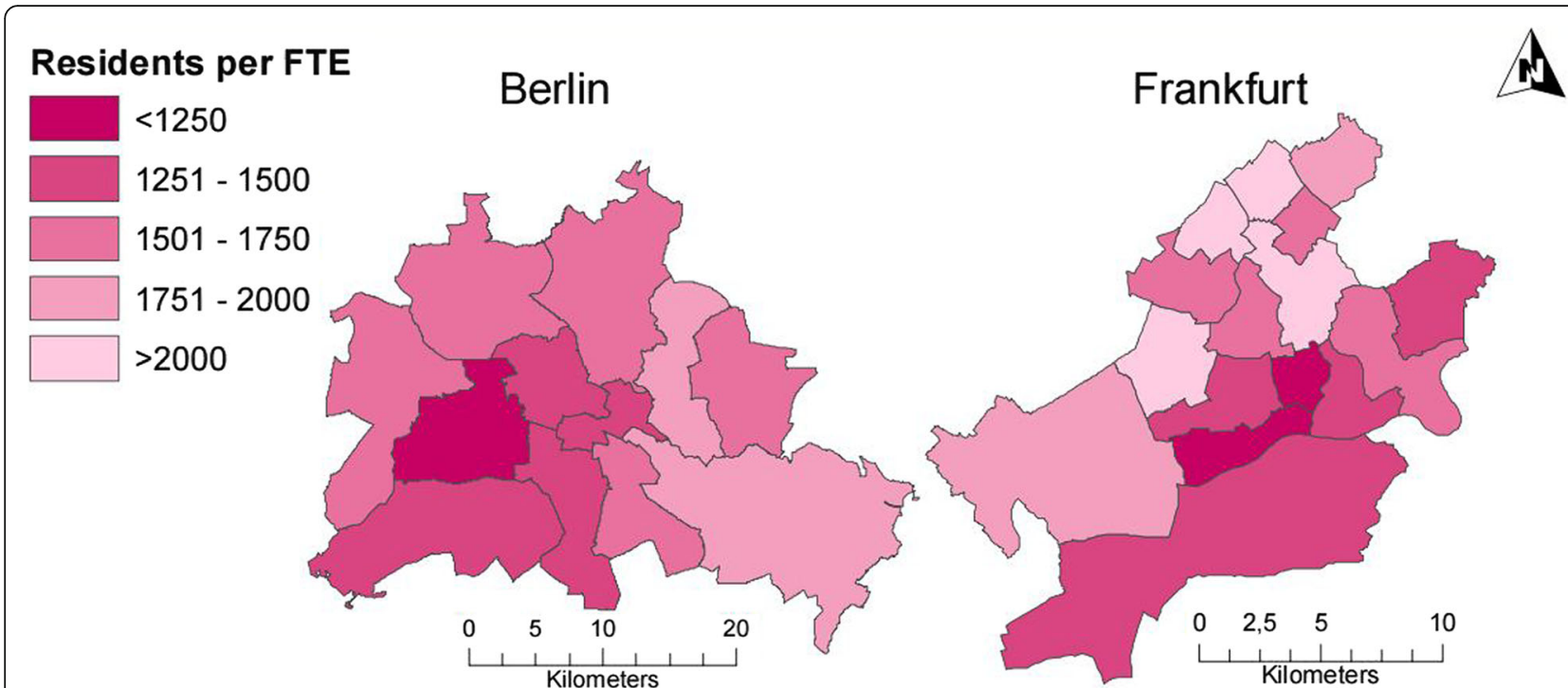

Fig. 3 Scatter plot of districts $(n=171)$ in regard to $z$-scores of GDI and GP density. GD/ geodemographic index, GP weighted capacity planning number of general practitioners

was $\mathrm{f}^{2}=0.70$, which indicated a strong effect. The regression analysis supported the finding that the distance to the city hall was the most important factor affecting the number of FTE per $10^{\wedge} 4$ residents on district level, followed by household size and benefits recipients' quota.

\section{Discussion}

The results of this study suggest that GPs are unequally distributed on inner-city level and equally distributed on inter-city level in German metropolitan areas with more than 500,000 residents. On district level, we documented that the distance to the city hall was the most important factor explaining higher GP densities, followed by household size and benefits recipients' quota. In this regard, the presented Geodemographic Index (GDI) could be used for planning purposes of GP health care services in urban areas.

\section{GP distribution on intra-city level}

We documented an unbalanced spatial distribution of GPs in terms of GP density in German metropolises on intra-city level. This finding is in line with current literature: A study conducted within Adelaide (Australia) found similar distribution patterns: $16 \%$ of residents were reported to live in an area of GP shortage within Adelaide boundaries [26]. An unbalanced distribution of physicians was further reported for Auckland (New Zealand) [27] and Toronto (Canada), where the authors reported a

Table 4 Correlation and regression analysis of PRR with measures of SES

\begin{tabular}{|c|c|c|c|c|c|}
\hline & & \multicolumn{2}{|c|}{ Correlation analysis } & \multicolumn{2}{|c|}{ Regression analysis } \\
\hline & & $r$ & $p$-value & beta & $p$-value \\
\hline \multirow[t]{2}{*}{ PPR } & GDI & -0.49 & $<0.001$ & - & - \\
\hline & CEl & -0.22 & 0.005 & - & - \\
\hline \multirow[t]{10}{*}{ PRR } & population density & 0.35 & $<0.001$ & -0.11 & 0.244 \\
\hline & distance to city hall & -0.50 & $<0.001$ & -0.31 & 0.012 \\
\hline & old age dependency ratio & -0.24 & 0.002 & 0.16 & 0.077 \\
\hline & migrant quota & -0.03 & 0.702 & - & - \\
\hline & household size & -0.50 & $<0.001$ & -0.30 & 0.006 \\
\hline & employment quota & 0.01 & 0.880 & - & - \\
\hline & unemployment quota & -0.20 & 0.011 & - & - \\
\hline & benefits recipients quota & -0.24 & 0.002 & -0.24 & 0.002 \\
\hline & motorization rate & -0.32 & $<0.001$ & -0.20 & 0.062 \\
\hline & mortality & -0.10 & 0.180 & - & - \\
\hline
\end{tabular}


range of $6.18-12.42$ GPs per $10^{\wedge} 4$ residents for the city districts of Toronto [28]. In our study, the number of FTE per $10^{\wedge} 4$ residents ranged between $1.80-43.98$ and therefore variation was higher compared to the Canadian study. However, we included 14 cities whereas the aforementioned studies only reported results from individual cities, which increased the likelihood of data variability. Still, our results can be considered more valid due to the bigger sample size.

Furthermore, the extent of the demonstrated distribution varied between the analysed cities. For example, the high variation in Munich could be due to a greater competition between GPs, which translated into higher GP densities near the city centre and vice versa. However, it has to be noted that the number of districts varied between the cities and especially the number of districts in Munich used in this study was higher compared to all other cities. This could explain the higher variation in Munich.

\section{GP distribution on inter-city level}

On inter-city level, the distribution of GP densities was balanced. In other words, there was only little variability in GP density data. We assume that this balanced GP distribution pattern was due to strict German health care regulations, which restrict GP numbers in certain areas such as larger cities. Such areas are defined "oversupplied" as soon as the population-to-GP ratio exceeds $1: 1671$ by $10 \%$ ( $\$ 11$ (4) of the 'directive of capacity planning'). In this case, GPs will not receive permission to establish practices in these areas.

In general, studies have shown that GPs as well as other medical specialties tend to be located in urban areas $[5,6]$. The data presented in our study revealed higher GP densities on city level: in our study the overall physician-to-population ratio (PPR) was 1:1550 (SD: 139.3). Compared to the aforementioned threshold value of $1: 1671$ (the 'optimum ratio') the ratio was exceeded by $7.8 \%$. Therefore, applying the definition of oversupply mentioned above, these cities cannot be considered oversupplied. However, it has to be noted that within national capacity planning, adjustments can be made according to demography and/or geography. Regarding the non-physician participation in primary care, they were shown to constitute the smallest share of primary care workforce in urban areas and were more likely to delivery primary care in rural areas [29]. Therefore, lack of primary care services in more rural areas could be compensated by non-physician workforces. This solution to GP workforce shortage has also been reported by recent literature [3, 4].

In addition to the aforementioned variation of district numbers, differing district sizes could conceal further variation. However, city district sizes and numbers are not standardized in Germany, which limits the inter-city comparison. Therefore, the heterogeneity of district sizes and numbers could have concealed inter-city variations.

\section{GP location choices}

Using socioeconomic indicators, a correlation with GP densities was present that could explain GP location choices on city district level. In regard to the GDI, a mild negative correlation was present $(r=-0.49)$ indicating a negative influence on GP location choices. Looking at the factors comprising GDI, the most important factor was a spatial factor ('distance to the city hall'). Therefore, our results suggested spatial factors to be more important than non-spatial factors. However, in a survey [23] among 117 physicians in Germany, 81\% of participants stated that neighborhood characteristics concerning the suitability for children and families was the most important factor regarding practice location choice. The high impact of the 'significant other' on GP location choices has also been reported by Smith et al. [30]. Furthermore, spatial factors such as 'proximity to work place of significant other' or 'proximity to city center' were reported to only play a minor role regarding GP location choices [23]. However, a study in Finland [31] further reported 'location of workplace' and 'being near a central hospital' as the 2nd and 6th most important factor for the GPs workplace choice. In addition, proximity to other health care providers (e.g. dentist, pharmacies, hospitals) was further reported to influence location choices of GPs [31, 32]. In our study, pharmacies, dentists, hospitals and the work place of GP spouses were not measured and therefore not controlled for. In summary, it can be stated that spatial factors as reported in our study are important factors influencing the practice location choice of GPs. However, taking further research into account, non-spatial factors seem to have an even greater impact compared to spatial factors. The non-spatial factors comprising the GDI, namely household size and population density, were also used as high loading factors in the urban index (UX) created by Schulz et al. [24]. In their study, no relevant correlation $(r=-0.13)$ between UX and the demand for GP services was present. Considering both UX and GDI, the reported findings suggested that household size and population density influence the GP practice location choice (i.e. provider supply), but have no influence on the populations' demand for health care services. Looking at other non-spatial factors, Gosden et al. [33] reported 'aversion to location in areas of high deprivation' as the most important factor influencing GP practice location choices. In our study, deprivation was mostly reflected by CEI. However, a weak correlation $(r=-0.22)$ was found, which suggests only a minor influence on practice location choices. Further factors include financial incentives often represented by the percentage of the population with 
private health insurance, which has been shown to explain $14 \%$ of the GP density variation in Germany, while thealth care needs' only explained less than 5.2\% [34].

It has to be noted that location choices of GPs can be influenced by both external and internal factors. Internal factors such as personal characteristics have been shown to play an important role in the workplace selection process [35]. However, in our article we did not control for internal factors and focused solely on external factors defined by neighborhood statistics.

In regard to mortality, our study found no correlation with the spatial distribution of GPs. This finding is in line with current literature which showed no significant difference of mortality (deaths per 100 beneficiaries) in regard to differing GP densities [36].

Finally, many countries limit the GPs' practice location choice in order to sustain equal access, regardless of a patients' living location. The degree of this limitation usually depends on the performance of the health care system in place: The more sophisticated the health care system, the more regulations are in place, which in turn limits the GPs practice location choices. China for example has a rather weak primary care system, whereas the United Kingdom and Germany have a rather strong primary care system $[6,22]$. Bearing this in mind, our results only reflect the situation in a developed health care setting.

Although GPs do not fulfill a formal compulsory gatekeeper function in Germany, their availability and accessibility play a crucial role in a populations' access to health care $[6,37]$. Hence, it can be assumed that an unbalanced distribution of GPs could translate into health inequities [38, 39]. A mismatched distribution of GPs constitutes a major challenge for public and community health. Thus, tailored strategies and policies are desperately needed to address these challenges.

\section{Limitations}

Population-to-provider ratios (PPR) have limitations in regard to the measurement of spatial accessibility $[16,40]$. As outlined by Guagliardo, limitations of PPR include 1) not accounted border crossing, 2) blindness to variabilities within bordered areas, 3) omission of distance/time and 4) fixation to geographical/administrative boundaries [16]. Especially the omission of border crossing in the presented approach represents a limitation. More sophisticated measurements, which addressed these issues, are based on gravity models such as the Two Step Floating Catchment Area (2SFCA) method [41]. Since in Germany the population-to-provider ratio is still widely used in research and in the political context, we used a PPR despite the known limitations. However, we acknowledge the great value of more sophisticated measures using geographic information systems. Furthermore, using airline distances instead of time distances, represents a distance measurement simplification and therefore a loss of accuracy must be assumed. However, airline distances have also been used in similar research [21].

In addition to the aforementioned limitations, there are four limitations that have to be further addressed: First, there is no best indicator for measuring SES. Residual confounding by unmeasured socioeconomic factors can only be minimized, not excluded. On area level, different single measurements or composite indicators have been established (e.g. English Index of Multiple Deprivation [42], Bavarian Index of Multiple Deprivation [43], Townsend Deprivation Index). However, due to insufficient data availability, none of the described composite indicators could be used for the nationwide inner-city analysis in Germany.

Furthermore, city district data were heterogeneous and therefore the accuracy of the results could be compromised. In regard to GP practice locations, the allocation to city district boundaries has limitations due to possible errors retrieving geo coordinates [44].

\section{Conclusion}

Intra-city distribution of GPs was skewed, which could affect the equality of access for the urban population. Furthermore, health services planners should be aware of location preferences of GPs within major urban conurbations. This could be helpful to understand and plan the delivery of health care services. For this process the presented Geodemographic Index (GDI) could be of use.

\section{Abbreviations}

CEl: Cultureeconomic Index; GDI: Geodemographic Index; GP: General Practitioner; KBV: National Association of Statutory Health Insurance Physicians; PCA: Principal component analysis; SES: Socioeconomic status; UK: United Kingdom

\section{Acknowledgements}

We would like to especially thank Mr. Pascal Schoepe, Mr. John Sebastian and Dr. med Bernhard Gibis for their support.

Funding

This study was not funded.

\section{Availability of data and materials \\ The datasets supporting the conclusions of this article are available on request from the authors.}

\section{Author's contributions}

$J B$ designed the study. JB, DB, DO and DAG wrote the manuscript. All authors read and approved the final version of the manuscript.

\section{Competing interest}

The authors declare that they have no competing interests.

Consent for publication

Not applicable.

Ethics approval and consent to participate

Since only official public data were used in this study, neither institutional board approval nor informed consent was required. 
Received: 11 May 2016 Accepted: 16 November 2016 Published online: 25 November 2016

\section{References}

1. Royal College of General Practitioners. Over 500 surgeries at risk ofclosure as GP workforce crisis deepens. [Internet]. 2014 [cited 2016 Feb 10]. Available from: http://www.rcgp.org.uk/news/2014/october/over-500-surgeries-at-riskof-closure-as-gp-workforce-crisis-deepens.aspx

2. Asaria M, Cookson R, Fleetcroft R, Ali S. Unequal socioeconomic distribution of the primary care workforce: whole-population small area longitudinal study. BMJ Open. 2016;6:e008783.

3. Bodenheimer T, Smith M. Primary care: proposed solutions to the physician shortage without training more physicians. Health Aff (Millwood). 2013:32:1881-6.

4. Auerbach D, Chen P, Friedberg M, Reid R, Lau C, Buerhaus P, et al. Nursemanaged health centers and patient-centered medical homes could mitigate expected primary care physician shortage. Health Aff (Millwood). 2013;32:1933-41.

5. Steinhaeuser J, Otto P, Goetz K, Szecsenyi J, Joos S. Rural area in a European country from a health care point of view: an adaption of the Rural Ranking Scale. BMC Health Serv Res. 2014;14:147.

6. Kringos D, Boerma W, Hutchinson A, Saltman B. Building primary care in a changing Europe. 38th ed. Copenhagen; 2015

7. Mackenbach J, Stirbu I, Roskam A, Schaap M, Menvielle G, Leinsalu M, et al. Socioeconomic inequalities in health in 22 European countries. N Engl J Med. 2008;358:2468-81.

8. Commission on Social Determinants of Health $(\mathrm{WHO})$. Closing the gap in a generation: health equity through action on the social determinants of health. Geneva; 2008. p. 1-246

9. Elgar FJ, Pförtner T-K, Moor I, De Clercq B, Stevens GW, Currie C. Socioeconomic inequalities in adolescent health 2002-2010: a time-series analysis of 34 countries participating in the Health Behaviour in School-aged Children study. Lancet. 2015;385:2088-296.

10. Lampert T, Kroll LE, von der Lippe E, Müters S, Stolzenberg H. Socioeconomic status and health: results of the German Health Interview and Examination Survey for Adults (DEGS1). Bundesgesundheitsbl. 2013;56:814-21.

11. Kivimäki M, Virtanen M, Kawachi I, Nyberg ST, Alfredsson L, Batty GD, et al Long working hours, socioeconomic status, and the risk of incident type 2 diabetes: a meta-analysis of published and unpublished data from 222120 individuals. Lancet Diabetes Endocrinol. 2015:3:27-34.

12. Addo J, Ayerbe L, Mohan KM, Crichton S, Sheldenkar A, Chen R, et al. Socioeconomic status and stroke. Stroke. 2012:43:1186-91.

13. Lantz P, Golberstein E, House J, Morenoff J. Socioeconomic and behavioral risk factors for mortality in a national 19-year prospective study of U.S. adults. Soc Sci Med. 2012;70:1558-66.

14. Association of Statutory Health Insurance Physicians of the North Rhine region. Need-Planning [Internet]. 2013 [cited 2015 Oct 27]. Available from: http://www.kvno.de/downloads/bedarfsplanung

15. Albrecht $M$, Nolting $H$, Schliwen $A$, Schwinger $A$. New structure of need planning-final report. Berlin; 2012

16. Guagliardo MF. Spatial accessibility of primary care: concepts, methods and challenges. Int J Health Geogr. 2004;3:3.

17. Laditka JN, Laditka SB, Probst JC. Health care access in rural areas: evidence that hospitalization for ambulatory care-sensitive conditions in the United States may increase with the level of rurality. Health Place. 2009:15:731-40.

18. Aboagye JK, Kaiser HE, Hayanga AJ. Rural-urban differences in access to specialist providers of colorectal cancer care in the United States. JAMA Surg. 2014;149:537.

19. Doescher MP, Andrilla CHA, Skillman SM, Morgan P, Kaplan L. The contribution of physicians, physician assistants, and nurse practitioners toward rural primary care: findings from a 13-state survey. Med Care. 2014;52:549-56.

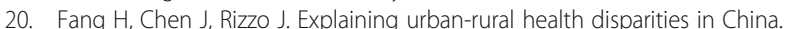
Med Care [Internet]. 2009:47:1209-16. Available from: http://www.ncbi.nlm. nih.gov/pubmed/19786910

21. Todd A, Copeland A, Husband A, Kasim A, Bambra C. Access all areas? An area-level analysis of accessibility to general practice and community pharmacy services in England by urbanity and social deprivation. BMJ Open. 2015;5:e007328.

22. Wang HHX, Wang JJ, Wong SYS, Wong MCS, Mercer SW, Griffiths SM. The development of urban community health centres for strengthening primary care in China: a systematic literature review. Br Med Bull. 2015;116:139-53.
23. Kistemann T, Schröer M-A. [Small-scale care by SHI physicians and their subjective choice of location within an oversupplied planning area]. Gesundheitswesen. 2007;69:593-600.

24. Schulz M, Czihal T, Erhart M, Stillfried D. Correlation between area-level sociodemographic patterns and estimates of need for medical care. Gesundheitswesen. 2016;78(5):290-7.

25. Bechtold K. GPSies-Tracks for Vagabonds [Internet]. 2014 [cited 2015 Aug 15]. Available from: http://www.gpsies.com

26. Roeger L, Reed R, Smith B. Equity of access in the spatial distribution of GPs within an Australian metropolitan city. Aust J Prim Heal. 2010;16:184-90.

27. Kruger E, Whyman R, Tennant M. High acuity GIS comparison of dentist and doctor surgery locations in Auckland, New Zealand. Community Dent Heal. 2013:30:83-7.

28. Gorey K, Luginaah I, Hamm C, Balagurusamy M, Holowaty E. The supply of physicians and care for breast cancer in Ontario and California, 1998 to 2006. Can J Rural Med. 2011;16:47-54.

29. Graves JA, Mishra P, Dittus RS, Parikh R, Perloff J, Buerhaus PI. Role of geography and nurse practitioner scope-of-practice in efforts to expand primary care. Med Care. 2016;54:81-9.

30. Smith B, Muma R, Burks L, Lavoie M. Factors that influence physician assistant choice of practice location. JAAPA. 2012;25:46-51.

31. Heikkilä TJ, Hyppölä H, Aine T, Halila H, Vänskä J, Kujala S, et al. How do doctors choose where they want to work? - Motives for choice of current workplace among physicians registered in Finland 1977-2006. Health Policy. 2014;114:109-17.

32. McKernan S, Kuthy R, Joshi M. Primary care providers: relationships in practice locations. J Am Dent Assoc. 2012;143:e8-e15.

33. Gosden T, Bowler I, Sutton M. How do general practitioners choose their practice? Preferences for practice and job characteristics. J Health Serv Res Policy. 2000;5:208-13.

34. Vogt $V$. The contribution of locational factors to regional variations in officebased physicians in Germany. Health Policy. 2016;120:198-204.

35. Mu C. The age profile of the location decision of Australian general practitioners. Soc Sci Med. 2015;142:183-93.

36. Chang C, Stukel TA, Flood AB, Goodman DC. Primary care physician workforce and Medicare beneficiaries' health outcomes. JAMA. 2011;305:2096-104.

37. Huff C. Direct primary care: concierge care for the masses. Health Aff (Millwood). 2015;34:2016-9.

38. Mohd Noor A, Sarker D, Vizor S, McLennan B, Hunter S, Suder A, et al. Effect of patient socioeconomic status on access to early-phase cancer trials. J Clin Oncol. 2013;31:224-30.

39. Saydah SH, Imperatore G, Beckles GL. Socioeconomic status and mortality: contribution of health care access and psychological distress among U.S. adults with diagnosed diabetes. Diabetes Care. 2013;36:49-55.

40. Guagliardo M, Ronzio C, Cheung I, Chacko E, Joseph J. Physician accessibility: an urban case study of pediatric providers. Health Place. 2004;10:273-83.

41. Luo W, Wang F. Measures of spatial accessibility to healthcare in a GIS environment: synthesis and a case study in Chicago region. Env Plann B. 2003;30:865-84

42. Galobardes B, Shaw M, Lawlor D, Lynch J. Indicators of socioeconomic position (part 2). J Epidemiol Community Heal. 2006;60:95-101.

43. Maier W, Fairburn J, Mielck A. Regional deprivation and mortality in Bavaria. Development of a community- based index of multiple deprivation. Gesundheitswesen. 2012;74:416-25.

44. McLafferty S, Freeman VL, Barrett RE, Luo L, Shockley A. Spatial error in geocoding physician location data from the AMA Physician Masterfile: implications for spatial accessibility analysis. Spat Spatiotemporal Epidemiol. 2012;3:31-8

45. Federal Ministry of Jutice and Consumer Protection. GeoNutzV [Internet]. 2016 [cited 2016 Nov 13]. Available from: http://www.gesetze-im-internet. de/geonutzv/_2.html

46. National Association of Statutory Health Insurance Physicians. Health Data-Need Planning Accounts for Participation in Medical Care [Internet]. 2015 [cited 2015 Nov 9]. Available from: http://gesundheitsdaten.kbv.de/ cms/html/17015.php 